\title{
EDITORIAL
}

\section{ERS is founding member of a new Alliance for Biomedical Research in Europe}

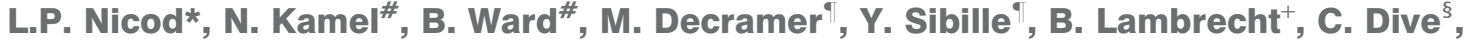 \\ U. Smith ${ }^{f}$ and K.R. Sipido**
}

$\mathbf{T}$ he Alliance for Biomedical Research in Europe (BioMed Alliance) was founded on December 9, 2010 by the four leading European medical academic societies: the European Association for the Study of Diabetes (EASD), the European Society of Cardiology (ESC), the European Respiratory Society (ERS) and the European CanCer Organisation (ECCO)

The BioMed Alliance intends to be a key stakeholder for biomedical research in Europe, and to coordinate and unify European medical societies in advocating for increased resources at both a national and European Union (EU)-level for biomedical research.

The first annual general meeting (AGM), held in Brussels, Belgium, on December 9, 2010, was attended by 32 European, academic, non-profit associations representing over 400,000 European researchers (a full list of these associations can be found in the Acknowledgements). Dr Ruxandra DraghiaAkli, Director of Health at DG Research of the European Commission, expressed her concern about current European funding earmarked for health projects, and emphasised that a formal consultation with the BioMed Alliance as a key stakeholder on the next EU Research Framework Programme would be welcomed [1].

At the AGM, the Brussels Declaration on European biomedical research was unanimously supported. The Declaration states that greater involvement of the research community is vitally needed to promote biomedical research in Europe, and to increase the level of funding and its quality, with the ultimate aim being improved quality of life for European citizens. The following areas of urgency were particularly highlighted.

1) The future of academic biomedical research is threatened by cuts in the research and education budgets of many EU member states.

\footnotetext{
*Faculté de Biologie et de Médecine, et de Pneumologie, Centre Hospitalier Universitaire Vaudois, Lausanne, Switzerland. "European Respiratory Society, Brussels. "Respiratory Division, University of Leuven. ${ }^{* *}$ Division of Experimental Cardiology, Dept of Cardiovascular Medicine, Katholieke Universiteit Leuven, Leuven. ${ }^{+}$Respiratory Division, University of Ghent, Ghent, Belgium. ${ }^{\S} \mathrm{Clinica}$ and Experimental Pharmacology Group, Paterson Institute for Cancer Research, Manchester, UK. ${ }^{f}$ Dept of Molecular and Clinical Medicine, Sahlgrenska University Hospital, Gothenburg, Sweden.

CORRESPONDENCE: L.P. Nicod, Faculté de Biologie et de Médecine, et de Pneumologie, Centre Hospitalier Universitaire Vaudois, 1011 Lausanne, Switzerland. E-mail: laurent.nicod@chuv.ch
}

2) Europe cannot afford continued underinvestment in biomedical research. Unless action is taken, European biomedical research stands to lose its competitiveness in the next decade, jeopardising the training and career prospects of a generation of European researchers.

3) Europe is facing major competition in the field of biomedical research at a global level, not only from North America, but increasingly from Asia, and particularly China. Only the USA's investment in biomedical research as a proportion of gross domestic product is almost three times higher than that in Europe [2].

The BioMed Alliance aims to change all of the above, by giving a single, powerful voice to the European biomedical research community, thereby maximising its impact on research budgets, in all health disciplines, for improved health and wellbeing of European citizens [3].

It will aim to engage with EU institutions, particularly the European Commission, the European Parliament and the Council, including the EU Presidencies, in upcoming and ongoing consultations, and on the next EU research and innovation funding programmes. In addition to seeking to meet with various European Commission officials of DG Research, the BioMed Alliance submit an official response to the first important public consultation on future EU research and innovation funding (http:/ / ec.europa.eu/research/csfri/ index_en.cfm), officially published on February 9, 2011.

The main objective of the Alliance's actions will be to provide structured input to the policy debate in order to help direct funds more fairly, adequately and sustainably, thereby addressing the common problem encountered by researchers. It is hoped these actions will ultimately improve the status of and funding for biomedical research in the EU Research Framework programme and raise the sense of urgency on this topic [1].

Other activities of the BioMed Alliance will be to forge relationships with key members of the European Parliament, particularly members of the Industry, Research and Energy (ITRE) committee, who will have a central decision-making role in the future EU research framework programmes. Other EU-based organisations, such as the European Medical Research Council (EMRC), which is part of the European Science Foundation (ESF), have been approached by the BioMed Alliance and are eager to collaborate on this important issue of strengthening medical research. 
The main targets of the BioMed Alliance are as follows.

1) Substantially increase the proportion of funding going to biomedical research in the next EU Framework Programme for research. EU funding for health research represents a mere $10 \%$ of the overall EU research funding budget (€6.1 billion out of $€ 53.2$ billion). In comparison, in the USA, the National Institutes of Health (NIH) invest on average 3.5 times more (US\$31.2 billion, the equivalent to $€ 21.5$ billion) than the EU (€6.1 billion) in health research.

2) Improve the quality of European funding for biomedical research by enhancing the participation of researchers in policy and decision-making at an EU level. Current procedures are too heavily burdened by complex administration and rules, e.g. a mechanism needs to be established to ensure the continuity of excellent collaborations via grant extensions. The BioMed Alliance also needs to be included in the impact assessment of the Seventh Framework Programme for Research (FP7).

3) Promote the best interests and values of researchers across all medical disciplines in Europe, and where common interests are identified. Better career structures for researchers should be developed, and support should be offered for MD/ PhD research professorships.

4) Facilitate and improve biomedical research in Europe, and develop an improved framework for better training and mobility of young researchers. Europe has the infrastructure and competence to distribute research funding by a fair peerreview system based on quality and scientific integrity. In addition, the infrastructure for biomedical research should be reinforced through the European Roadmap for Research Infrastructures (ESFRI).

The role of ERS as a founding member will be to coordinate relations with the European Parliament (EP) on behalf of the BioMed Alliance. The EP has a decisive and influential role in the decision-making process of the EU.

ERS is well placed to further strengthen the ties of the BioMed Alliance with the EP, given its prior experience and engagement with the EP during 2010 Year of the Lung (www. yearofthelung.org), when ERS organised a policy seminar entitled "Research and Respiratory Medicine: Addressing future challenges for improved lung health". The event, cohosted by members of the EP (MEPs) Prof. Ioannis Tsoukalas (Greece) and Satu Hassi (Finland), represented a huge success, not least because several representatives from national respiratory societies across Europe participated, which was instrumental in engaging and attracting other MEPs to attend.

Moreover, on September 7, 2011, MEP Catherine Stihler (UK) will be co-hosting the official launch in the EP of the European Respiratory Roadmap. The Roadmap provides concrete policy recommendations not only for the next decade of research in respiratory medicine, but also for prevention, clinical care, and education.

The launch of the Roadmap will be an opportunity to emphasise how biomedical research can offer solutions to society's big challenges, tackle the problem of an ageing population and contribute towards a productive and healthy workforce. We must act now to reinforce Europe as a global and scientifically competitive leader. For progress to be effective, our collective vision and leadership is a must.

\section{STATEMENT OF INTEREST}

A statement of interest for M. Decramer can be found at www.erj. ersjournals.com/site/misc/statements.xhtml

\section{ACKNOWLEDGEMENTS}

L.P. Nicod is ERS Scientific Committee Chair and a Member of the Board of the Alliance for Biomedical Research (BioMed Alliance) on behalf of ERS; M. Decramer is ERS President; Y. Sibille is ERS EU Secretary; B. Lambrecht is Scientific Relations Director for the EU; C. Dive is a Board member of the BioMed Alliance on behalf of the European CanCer Organisation (ECCO); U. Smith is President of the BioMed Alliance on behalf of the European Association for the Study of Diabetes (EASD); K.R. Sipido is a Board member of the BioMed Alliance on behalf of the European Society of Cardiology (ESC).

The BioMed Alliance was founded on December 9, 2010, at its first annual general meeting (AGM) by four leading European medical academic societies: the European Association for the Study of Diabetes (EASD), the European Society of Cardiology (ESC), the European Respiratory Society (ERS), and the European CanCer Organisation (ECCO). The following 28 other societies/federations/bodies were also represented at first the AGM: European Society of Anaesthesiology (ESA); European Society of Cataract and Refractive Surgery (ESCRS); European Strategy Forum on Research Infrastructures (ESFRI); European Society of Gynaecology (ESG); European Society of Hypertension (ESH); European Society of Human Reproduction and Embryology (ESHRE); European Society for Medical Oncology (ESMO); European Stroke Organisation (ESO); European Society of Pathology (ESP); European Society of Paediatric Research (ESPR); European Society of Radiology (ESR); European League Against Rheumatism (EULAR); Federation of European Biochemical Societies (FEBS); Federation of European Neuroscience Societies (FENS); European AIDS Clinical Society (EACS); European Association for Cardiothoracic Surgery (EACTS); European Association of Nuclear Medicine (EANM); European Athersclerosis Society (EAS); European Association for Study of The Liver (EASL); European Association for the Study of Obesity (EASO); European Group for Blood and Marrow Transplantation (EBMT); European College of Neuropharmacology (ECNP); European Federation of Immunological Societies (EFIS); European Federation of Neurological Societies (EFNS); European Hematology Association (EHA); European Kidney Health Alliance (EKHA); European Molecular Biology Organization (EMBO); European Research Council (ERC).

\section{REFERENCES}

1 Kirby T. European societies form biomedical alliance. Lancet 2011; 377: 541-542.

2 Health Economics Research Group, Office of Health Economics, RAND Europe. Medical research: what's it worth? Estimating the economic benefits from medical research in the UK. London, UK Evaluation Forum, 2008.

3 Major European medical Societies form Alliance to improve stagnant research funding, and prevent EU research being left behind by China. Lancet Press Release. www.biomedeurope.org/ Press/ALLIANCE.pdf Date last updated: December 20, 2010. Date last accessed: April 21, 2011. 